\title{
EARLY POST-OPERATIVE WOUND INFECTION IN ORTHOPAEDIC IMPLANT SURGERY AND ITS COMPLICATION
}

\author{
Rajesh Jain, Dinesh Sonkar
}

1. Assistant Professor. Department of Orthopaedics, Govt. Bundelkhand Medical College, Sagar, Madhya Pradesh.

2. Professor \& Head. Department of Orthopaedics, Govt. Bundelkhand Medical College, Sagar, Madhya Pradesh.

\section{CORRESPONDING AUTHOR:}

Dr. Rajesh Jain,

Flat N-10 Type 3 B Block, Doctor's Residence BMC, Sagar, Madhya Pradesh.

E-mail: dr_rajesh_jain@yahoo.com

ABSTRACT: INTRODUCTION: Bone infections after implant surgery leading to nonunion and implant failure is one of the most challenging Orthopaedic complications. This study is done to find out relation of type of pathogens causing postoperative infection with that of fracture nonunion, chronic osteomylities and implant failure. METHODOLOGY: This is a retrograde study of 20 cases, in which post operative wound infection occurred after implant surgery from 2009 to 2012. Results: Out of 20 postoperative infected cases, 12 were infected by S ' \aureus, 2 by pseudomonas and 1 from E-coli. 5 cases had their culture sterile. Out of 12 cases infected by S. aureus 7 developed infected non union in which 4 had serious infection also leading to chronic osteomylities. 5 cases of $S$ aureus infection got cured after implant removal following union. CONCLUSION: Most of the postoperative wound infections are caused by S. aureus. 2-.S. aureus is the commonest organism isolated from infected non-union. Majority have early onset of infection. 3-Early culture positive infection (within seven days after surgery) have poor out come.4- In our setup S Aurous strain is sensitive to linezolid, clindamycin and vancomycin. 5The use of ceftriaxone for preoperative surgical prophylaxis in orthopaedic implant surgery is questionable.6- The ideal strategy for S. aureus infected implant is lacking. By surgical debridement, culture sensitivity specific antibiotic for 6 to 8 week and retention of implant, union were not achieved in majority of cases. 7-New approach is required for prevention and management of postoperative $\mathrm{S}$. aureus infected implant.

KEYWORDS: Microbiology; Infection; S.aureus; Nonunion; Sensitivity; Causes; Prevention

INTRODUCTION: Bone infection after implant surgery leading to nonunion and implant failure is one of the most challenging Orthopaedic complications. Chronic posttraumatic osteomyelitis and infected nonunion of the tibia result in considerable morbidity and can threaten viability of the limb [1]. Although definitions vary, non union has been aptly described as a fracture in which the reparative process has come to complete standstill [2]. In well established cases there are well defined radiological and histological signs which dictate the surgical procedure. Infected nonunion has been defined as a state of failure of union and persistence of infection at the fracture site for 6 to 8 months [3]. By definition infected non-union is a Cierney - Mader type 4 osteomyelitis [4] (meaning that diffuse osteomyelitis involves the entire thickness of the bone, with loss of stability). 
Factors involved with fracture non-union include, systemic condition like diabetes, smoking ,nicotine use, malnutrition, osteoporosis, use of non steroidal anti inflammatory agent, and local condition like infections, devascularisation of fracture fragment, poor stabilization, poor bone contact, iatrogenic factors, magnitude of trauma and biofilm formation on implant $[5]$.

Development of infection may result from compromised soft tissue and bone vascularity, systemic compromise of the host, and virulent or resistant organisms [6]. Multiple risk factors for orthopaedic surgical site infection have been identified. These include diabetes, malnutrition ( a total lymphocytes count of $<1500 \mathrm{~mm}^{3}$, serum albumin label $<3.5 \mathrm{~g} / \mathrm{dl}$ or serum transferring label of $<226 \mathrm{mg} / \mathrm{dl}$ ), use of tobacco, obesity, nasal carriage of $\mathrm{S}$. aureus, preoperative and postoperative anaemia and urinary tract infection[7]. The particular surgeon, the length of time that the wound is open and improper use of antibiotics was shown to be significant factors in the incidence of infection [8].

This study is done to find out relation of the type of pathogens causing postoperative infection with that of fracture non-union, chronic osteomyelitis and implant failure.

MATERIAL AND METHODS: This is a retrospective study of 20 cases, in which post operative wound infection occurred after implant surgery from 2009 to 2012. The criteria for the diagnosis of post-operative wound infection were those used by the National Research Council [9] of USA who defined POWI as "the presence of pus in a wound which has either discharged spontaneously or has to be released by the removal of sutures or re-opening the incision".

Cases with close or open Gustilo and Anderson type 1, 2 fractures were included in this study. All open fracture had pre-operative wound culture and sensitivity done, which was negative. All had low to medium velocity trauma. These include, 3 cases of fracture shaft femur, two treated by closed interlocking femur nailing and one by femur plating, 9 cases of fracture tibia fibula, five treated by plating and four by tibial interlock nailing, 5 cases of fracture shaft humerus ,two treated by Rush nail and three by DCP plating, 1 case of fracture of both bone in forearm, treated by forearm plating, 1 case of fracture of intertrochanteric femur treated by dynamic hip screw with side plate and 1case of old dislocation of elbow treated by Bhakshi sloppy hinge total elbow replacement. All cases were in the age group of 20 to 50 years. All patients otherwise had no other medical illness and good nutritional status. 8 cases had history of smoking.

Out of 20 postoperative infected cases, 12 were infected by S. aureus, 2 by pseudomonas and 1 from E-coli. 5 cases were found to be sterile on culture. Out of 12 cases infected by S. aureus, 7 developed infected non union in which 4 had serious infection leading to chronic osteomyelitis. 5 cases of S aureus infection got cured after implant removal following union. In 3 cases with postoperative Gram negative infection, infection subsided gradually by local dressing and use of appropriate antibiotics i.e., Amikacin and piperacillin, for one week and piperacillin alone for another one week or following implant removal in one case of tibial plating. In all 7 cases of infected non-union, infection occurred early, within 7 days of surgery. All theses S. aureus infection were sensitive to linezolid and clindamycin which was used for the duration of 6 to 8 weeks or till antibiotic resistance developed. Details of antibiotic sensitivity have been shown in table 1. All patients planned for surgeries in the department received prophylactic ceftriaxone preoperatively and ceftriaxone and amikacin for 3 days after surgery. 
DISCUSSION: Bone is normally resistant to infection [10]. However trauma, orthopaedic surgery, or placement of a foreign body such as an orthopaedic implant may expose this otherwise sterile environment to infection.

S. aureus is a common human pathogen which lives harmlessly on the skin and mucous membranes of healthy individuals [10]. S. aureus is Gram positive cocci [11]. From 1990-1992, data from the National Nosocomial Infections Surveillance System for the Centers for Disease Control and Prevention (CDC) revealed that $S$ aureus was the most common cause of operative wound infections and the second most common cause of nosocomial bloodstream infections [11].

A.D. Khoshrabi et al [12].in their article "study of bacteria isolated from orthopaedic implant infections and their antimicrobial susceptibility pattern" found S. aureus was the most common recovered bacterium with most sensitivity to vancomycin. In relation to one set of infection about $79 \%$ of patients were have early infection.

These findings were in accordance to our study in which $95 \%$ have early onset of infection. Majority of the cases were infected by $\mathrm{S}$. aureus which was sensitive to vancomycin and linezolid.

Venkatachalapaty et al[13] in their study "Factor causing non-union of fractures" found that although bone infection do not cause non-union per se. it can contribute to fracture nonunion through bone death, pus formation, creation of bone gap by osteolytic infection, granulation tissue and movement of loosening implant. Inflammatory response to bacteria at the site of fracture, disrupt callus, increased gap and motion between fragments causes fracture non-union. Infection causes poor bone quality resulting in implant failure.

A study conducted by Tania Claro, Amro Widaa, et al [10]. Department of Molecular and Cellular Therapeutics, Royal College of Surgeons in Ireland, - "Staphylococcus aureus Protein A, Binds to Osteoblasts and Triggers Signals That Weaken Bone in Osteomyelitis" found that major S. aureus virulence protein, SpA also binds directly to osteoblasts. This interaction results in the generation of multiple signals leading to inhibition of osteoblast proliferation $[14,15]$,induction of osteoblast apoptosis, inhibition of mineralisation and release of mediators capable of inducing bone resorption via osteoclast activation. Mineralisation is a process where phosphate and calcium becomes deposited in bone. This gives the bones additional strength and rigidity. During S. aureus infection, mineralisation (phosphate and calcium deposition) is completely inhibited. Our study supports that staphylococcus aureus interferes with fracture union.

Andrej Trampuz et al [16] in their study 'Infection associated with orthopaedic implant' found that prosthetic joint infection (early infection: within three months) is mainly caused by S. aureus .Implant associated infection are typically caused by microorganism growing in structure, known as biofilm. The treatment of implant associated infection require appropriate surgical intervention combined with prolong antimicrobial regime depends on pathogenesis of infection, stability of the implant, antimicrobial susceptibility of the pathogens and condition of surrounding soft tissue.

Marschall Berkes, William T. Obremskey et al [17] in their study "Maintenance of hardware after early postoperative infection following fracture internal fixation" found that deep infection after internal fixation of a fracture can be treated successfully with operative debridement, antibiotic suppression, and retention of hardware until fracture union occurs.

In our study postoperative implant infection were treated by surgical debridement, culture sensitivity specific antibiotic for 6 to 8 week and retention of implant till union achieved. By this strategy union were achieved in all the 5 sero negative, 3 Gram negative and 5 S. aureus 
infected cases. But 7 (58.33\%) cases of S. aureus infection went to nonunion. Of these 7 cases of non union, 4 had fracture tibia, fibula and 2 had fracture shaft humerus. In view of high rate of non- union staphylococcus aureus infected implant in fracture tibia fibula and fracture shaft humerus there is a need of different management protocol.

In our setup we used ceftriaxone for preoperative surgical prophylaxis and 3 days postoperative period. As majority of postoperative wound infection were caused by staphylococcus aureus which was resistant to ceftriaxone, the use of Ceftriaxone in orthopaedic implant surgery for preoperative prophylaxis is questionable.

Ceftriaxone displays poor penetration into infected cortical bone. Penetration was satisfactory in highly vascularised cancellous bone. Drug penetration is impaired in necrotic bone and sequester. (Garazzino $S$ et al [18] Ceftriaxone penetration in patient with septic non union of tibia")

Trampuz A et al [19] in their study "Antimicrobial agents in orthopaedic surgery: Prophylaxis and treatment" found that the pathogenesis of implant-associated infection involves interaction between the microorganisms (biofilm formation), the implant and the host. Despite improvement of perioperative prophylaxis, orthopaedic implants still remain highly susceptible to bacterial or fungal contamination, generally resulting in persistent implantassociated infection. Therefore, perioperative and life-long prevention of infection is important. Increasing antimicrobial resistance to first- or second-generation cephalosporin requires the use of alternative agents, such as quinupristin/dalfopristin, linezolid, and daptomycin, for perioperative prophylaxis. But results of clinical trials with these agents are limited. Also reviewed are potential new antimicrobial agents currently undergoing investigation, such as the novel oxazolidinone RWJ-416457, the new glycopeptide dalbavancin, the glycylcycline compound tigecycline, the new carbacephem BP-102 and novel rifamycin derivatives. Vaccination against Staphylococcus aureus with StaphVAX induced specific antibodies potentially preventing bacteraemia; however, there are no studies on efficacy in the prophylaxis of device-associated infections with this vaccine.

We agree with Trampus $A$ et al that we further require new strategy to prevent and manage postoperative implant infection.

CONCLUSION: The results of the present study can be concluded as follow;

1-Most of the postoperative wound infections are caused by Staphylococcus aureus.

2-S. aureus is the commonest organism isolated from infected non-union.

3-Majority have early onset of infection.

4-Early culture positive infection (within seven days after surgery) has poor out come.

5-In our setup $S$ aureus strain is sensitive to linezolid, clindamycin and vancomycin.

6-The use of ceftriaxone for preoperative surgical prophylaxis in orthopaedic implant surgery is questionable.

7-The ideal strategy for post operative staphylococcus aureus infected implant is lacking. By surgical debridement, culture sensitivity specific antibiotic for 6 to 8 week and retention of implant, union was not achieved in majority of post operative $S$. aureus infected cases.

8- New approach is required for prevention and management of postoperative S. aureus infected implant. 
LIMITATION: This is a small study. A larger study, to reach conclusion regarding, an ideal approach for the prevention and the management of postoperative S. aureus infected implant is needed.

\section{REFERENCES:}

1. Lew DP, Waldvogel FA (2004); Osteomyelitis. Lancet.2004 Jul 24-30;364(9431):36979.http://www.ncbi.nlm.nih.gov/pubmed/15276398

2. Stanley Hoppenfeld; Orthopaedic dictionary page 277

3. Struijs PA, Poolman RW, Bhandari M: Infected nonunion of the long bones. J Orthop Trauma., 2007, Aug; 21(7):507-11

4. Cierny G, III, Mader J T, Penninck J: A clinical staging system for adult osteomyelitis. Clin Orthop Relat Res. 2003;414:7-24.[PubMed]

5. Brian Mawalla, Stephen E Mshana, E Mshana*, Phillipo L Chalya: Predictors of surgical site infections among patients undergoing major surgery at Bugando Medical Centre in Northwestern Tanzania BMC Surgery 2011,www.biomedcentral.com/1471$2482 / 11 / 21$

6. Patzakis MJ, Zalavras CG: Chronic posttraumatic osteomyelitis and infected nonunion of the tibia: current management concepts. J Am Acad Orthop Surg. 2005 Oct;13(6):417-27. http://www.ncbi.nlm.nih.gov/pubmed/16224114

7. Richard P. Evans: Surgical site infection prevention and control: an emerging paradigm, J Bone joint Surg Am.2009;91::2-9. Doi: 10. 2106/ JBJS. I.00549

8. David B. Stevens: Postoperative Orthopaedic Infections, A study of etiological mechanisms, J Bone Joint Surg Am, 1964 Jan 01;46(1):96-102

9. National Academy of Sciences, National Research Council, Division of Medical Sciences, Ad Hoc Committee on trauma, post-operative wound infection: the influence of ultraviolet irradiation on the operating room and of various other factors. Ann Surg 1964; 160 (suppl 2)

10. Claro T, Widaa A, O'Seaghdha M, Miajlovic H, Foster TJ, et al. (2011): Staphylococcus aureus Protein A Binds to Osteoblasts and Triggers Signals That Weaken Bone in Osteomyelitis. PLoS ONE 6(4): e18748. doi:10.1371/journal.pone.0018748

11. Robert W Tolan Jr, Russell W Steele: Staphylococcus aureus infection, medscape reference. http://emedicine.medscape.com/article/971358-overview

12. A.D. Khosravi, F. Ahmadi, S. Salmanzadeh, A. Dashtbozorg and E. Abasi Montazeri, 2009: Study of Bacteria Isolated from Orthopedic Implant Infections and their Antimicrobial Susceptibility Pattern. Research Journal of Microbiology, 4: 158-163

13. Venkatachalapaty et al. in their study: Factor causing non-union of fractures, current orthopaedics(2007)21,258-261.

14. Tucker KA, Reilly SS, Leslie CS, Hudson MC (2000): Intracellular Staphylococcus aureus induces apoptosis in mouse osteoblasts. FEMS Microbiol Lett 186: 151-156.

15. Alexander EH, Rivera FA, Marriott I, Anguita J, Bost KL, et al. (2003): Staphylococcus aureus - induced tumor necrosis factor - related apoptosis - inducing ligand expression mediates apoptosis and caspase-8 activation in infected osteoblasts. BMC Microbiol 3: 5.

16. Andrej Trampuz, Andreas F widmer: Infection associated with orthopaedic implant. Curr Opin Infect Dis 19:349-356. _ 2006 Lippincott Williams \& Wilkins. 
17. Marschall Berkes, et al: Maintenance of hardware after postoperative infection following fracture internal fixation. Jbjs Am,2010apr 01,92(4)

18. Garazzino S, Aprato A, Baietto L, D'Avolio A,et al: Ceftriaxone bone penetration in patients with septic non-union of the tibia. Int J Infect Dis. 2011 Jun;15(6):e415-21. Epub 2011 Apr 15

19. Trampuz A, Zimmerli W: Antimicrobial agents in orthopaedic surgery: Prophylaxis and treatment. Pubmed ,Drugs. 2006;66(8):1089 www.ncbi.nlm.nih.gov/pubmed/16789794

Table 1RELATIONSHIP BETWEEN FRACTURE, PROCEDURE DONE, INFECTIVE AGENTS, SENSITIVE ANTIBIOTICS AND COMPLICATION

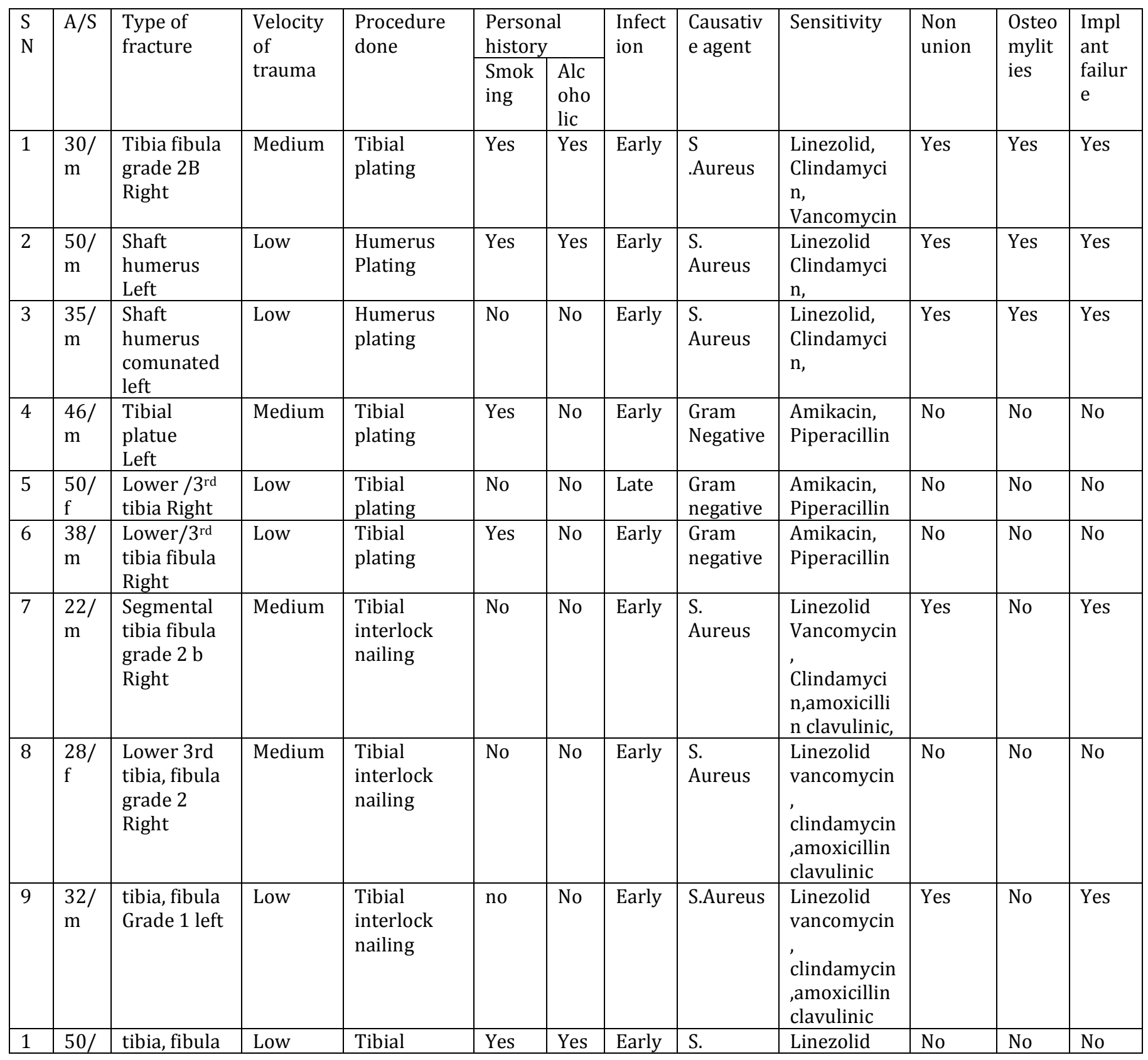




\begin{tabular}{|c|c|c|c|c|c|c|c|c|c|c|c|c|}
\hline 0 & $\mathrm{~m}$ & Left & & $\begin{array}{l}\text { interlock } \\
\text { nailing }\end{array}$ & & & & Aureus & $\begin{array}{l}\text { vancomycin } \\
\text { ' } \\
\text { clindamycin } \\
\text {,amoxicillin } \\
\text { clavulinic }\end{array}$ & & & \\
\hline $\begin{array}{l}1 \\
1\end{array}$ & $\begin{array}{l}35 / \\
\mathrm{m}\end{array}$ & $\begin{array}{l}\text { Both bone } \\
\text { forearm } \\
\text { Left }\end{array}$ & Low & $\begin{array}{l}\text { Both bone } \\
\text { forearm } \\
\text { plating }\end{array}$ & Yes & Yes & Early & $\begin{array}{l}\text { S. } \\
\text { Aureus }\end{array}$ & $\begin{array}{l}\text { Linezolid, } \\
\text { clindamycin } \\
\text {,ofloxacin }\end{array}$ & No & No & No \\
\hline $\begin{array}{l}1 \\
2\end{array}$ & $\begin{array}{l}28 / \\
\mathrm{f}\end{array}$ & $\begin{array}{l}\text { shaft femur } \\
\text { Left }\end{array}$ & Medium & $\begin{array}{l}\text { Femur } \\
\text { platting }\end{array}$ & No & No & Early & Sterile & No growth & No & No & No \\
\hline $\begin{array}{l}1 \\
3\end{array}$ & $\begin{array}{l}48 / \\
m\end{array}$ & $\begin{array}{l}\text { Old } \\
\text { dislocation } \\
\text { elbow Right }\end{array}$ & Low & $\begin{array}{l}\text { Total elbow } \\
\text { replacemen } \\
\mathrm{t}\end{array}$ & Yes & Yes & Early & $\begin{array}{l}\text { S. } \\
\text { Aureus }\end{array}$ & $\begin{array}{l}\text { Linezolid, } \\
\text { imipenem }\end{array}$ & Yes & - & \\
\hline $\begin{array}{l}1 \\
4\end{array}$ & $\begin{array}{l}38 / \\
m\end{array}$ & $\begin{array}{l}\text { shaft femur } \\
\text { Left }\end{array}$ & Medium & $\begin{array}{l}\text { Femur } \\
\text { interlock } \\
\text { nailing }\end{array}$ & No & No & Early & Sterile & No growth & No & No & No \\
\hline $\begin{array}{l}1 \\
5\end{array}$ & $\begin{array}{l}28 / \\
\mathrm{m}\end{array}$ & $\begin{array}{l}\text { Inter- } \\
\text { trochenteric } \\
\text { femur Left }\end{array}$ & Medium & DHS & No & No & Early & Sterile & No growth & No & No & No \\
\hline $\begin{array}{l}1 \\
6\end{array}$ & $\begin{array}{l}30 / \\
\mathrm{m}\end{array}$ & $\begin{array}{l}\text { shaft } \\
\text { humerus } \\
\text { Right }\end{array}$ & Low & $\begin{array}{l}\text { Rush } \\
\text { nailing }\end{array}$ & Yes & Yes & Early & Sterile & No growth & No & No & No \\
\hline $\begin{array}{l}1 \\
7\end{array}$ & $\begin{array}{l}28 / \\
m\end{array}$ & $\begin{array}{l}\text { shaft } \\
\text { humerus } \\
\text { Left }\end{array}$ & Low & $\begin{array}{l}\text { Rush } \\
\text { nailing }\end{array}$ & No & No & Early & $\begin{array}{l}\text { S. } \\
\text { Aureus }\end{array}$ & $\begin{array}{l}\text { Linezolid, } \\
\text { clindamycin }\end{array}$ & No & No & No \\
\hline $\begin{array}{l}1 \\
8\end{array}$ & $\begin{array}{l}38 / \\
\mathrm{f}\end{array}$ & $\begin{array}{l}\text { shaft } \\
\text { humerus } \\
\text { right }\end{array}$ & Medium & Plating & No & No & Early & $\begin{array}{l}\mathrm{S} \\
\text {.Aureus }\end{array}$ & $\begin{array}{l}\text { Linezolid, } \\
\text { clindamycin } \\
\text {, ofloxacin }\end{array}$ & No & No & No \\
\hline $\begin{array}{l}1 \\
9\end{array}$ & $\begin{array}{l}28 / \\
\mathrm{m}\end{array}$ & $\begin{array}{l}\text { shaft femur } \\
\text { left }\end{array}$ & Medium & $\begin{array}{l}\text { Interlock } \\
\text { nailing }\end{array}$ & No & No & Early & Sterile & No growth & No & No & No \\
\hline $\begin{array}{l}2 \\
0\end{array}$ & $\begin{array}{l}45 / \\
\mathrm{m}\end{array}$ & $\begin{array}{l}\text { Tibia, fibula } \\
\text { Right }\end{array}$ & Low & $\begin{array}{l}\text { tibial } \\
\text { interlock } \\
\text { nail }\end{array}$ & yes & yes & Early & $\begin{array}{l}\text { S. } \\
\text { Aureus }\end{array}$ & $\begin{array}{l}\text { Linezolid, } \\
\text { clindamycin } \\
\text {, ofloxacin }\end{array}$ & yes & Yes & No \\
\hline
\end{tabular}

